surrounding the thickness of the thigh, indicated the place at which the wheel passed over the limb. General condition good; temperature $102^{\circ} \mathrm{F}$. On the 15 th he was doing well; there was a plentiful discharge, which was becoming purulent, but was quite sweet. On the 16 th the femoral artery was felt beating strongly in the wound; and on the $20 \mathrm{th}$ there was considerable bleeding from a branch of femoral artery, which was exposed and ligatured. The general condition was good. On the 27th the limb, which had been dressed daily, was placed on Dr. Heath's (of Newcastle-onTrne) splint.

On Jan. 11th, 1880, the patient expressed himself as being much more comfortable in the new splint. The wound was healing slowly, and the pulsation in femoral artery was less. The general condition was much improved.

From this time the wounds gradually closed, and the discharge diminished; the patient's general condition became daily more comfortable, the appetite was good, and the pulse regular and gond.

From Feb. 2nd the limb was dressed at intervals of three days.

On May 13th two necrosed fragments of bone came away, and the splint was taken off, and the limb was laid between sandbags.

On June 2óth there was good union, with three-auarters of an inch shortening. The wounds had contracted into sinuses, and the femoral artery appeared to be thrombosed at the seat of injury. The general health of the patient was extremely satisfactory.

\section{TYRONE COUNTY INFIRMARY.}

CASI OF STRANGULATED FEMORAL HERNIA ; OPERATION WITHOUT OPENING THE SAC; RAPID RECOVERY.

(Under the care of Dr. Eoward ThoMpson.)

JAMES $\mathrm{F}$ - aged fifty-five, a delicate, decrepit-looking old man was admitted on May 15th, 1880, suffering from great sickness, with violent pain in the lower part of the abdomen. The day previous to his admission he was making some unusual exertion when he experienced a sudden pain in the abdomen as if something had given way, and was almost immediately seized with sickness and a feeling of faintness. He sought advice at the dispensary of the district, and was there recommended to the hospital.

On admission the face was pale and anxious, the pulse fluttering and very feeble, and the extremities were cold. There was constant vomiting, together with pain on pressure, over the lower part of the abdomen. The bowels had not moved since the previous day. Temperature $99^{\circ}$; urine diminished in quantity. In the usual situation a very small femoral heruia was readily detected. Taxis having proved ineffectual, it was determined to delay operative interference no longer.

The patient was accordingly put under the influence of ether, and the operation was done with the usual antiseptic precautions. The skin over the hernia was incised, and the structures overlying the sac were then carefully divided on a director until the sac was reached. The nail of the indexfinger was then introduced under the edge of Gimbernat's ligament, aud the stricture fieely divided with Cooper's knife. The intestine was at once reduced, and a drainagetube was inserted, and the edges of the incision were brought together by three silver wire-sutures. The wound was then dressed antiseptically, and the patient removed to his bed feeling much relieved.

After the operation all sickness ceased, and rapid reaction from extreme collapse set in. The extremities became warm, the uulse quickly improved, and the peculiar anxious expression of countenance soon faded away. The patient was ordered a grain of opium every fourth hour, and small quantities of milk frequently.

The morning after the operation the temperature rose to $995 \mathrm{~F}$, hut in the evening it was normal, the bowels having acted of themselves in the meantime. In a week the patient was out of hed, and the wound was quite healed.

Remarlis by Dr. Thompson. - I hare had many cases of hernia requiring operation, but unfortunately hitherto at least 50 per cent. of them bave proved fatal; nor is this percentage, large as it undoubtedly is, in any way remarkable, for I feel convinced that if the statistics of operations for strangulated femoral and inguinal hernia were fairly recorded, the unsuccessful as well as the successful, the mortality would at least reach the percentage I have stated. This excessive death.rate can, without doubt, be accounted for-first, owing to the common practice of opening the sac; and, secondly, the non-employment of Lister's antiseptic precautions. The case just recorded seems to demonstrate the advantages resulting from both these proceedings. There are of course cases which require the opening of the sac; for instance, where the hernia is an old one, and the strangulation has existed for many days, or again, if the intestine is gangrenous. In the former case there may be bands within the sac itself, binding down the intestine, and keeping up the symptoms of strangulation, even when the stricture has been freely divided. In the second case the sac must be opened in order to incise the gargrenous intestine for the purpose of forming an artificial anus. There can, I think, be ne doubt that the modern practice of not opening the sac in recent cases of strangulated hernia is the right one.

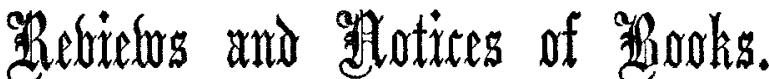

Practical Lithotomy and Lithotrity: or an Inquiry into the best modes of Removing Stone from the Bladder. By Sir HENRY THOMPSON, F.R.C.S., Surgeon Extraordinary to His Majesty the King of the Belgians, Emeritus Professor of Clinical Surgery, and Consulting Surgeon to University College Hospital, \&c. \&c. Third Edition, considerably enlarged. London: J. \& A. Churchill. 1880.

THE worth of this treatise has been so well and long recognised that the work of a reviewer of a third edition of it is considerably simplified. Sir Henry Thompson's views, too, are tolerably generally known, for his annual course of lectures at University College Hospital and communications to our columns and various societies have enabled him to publish the fruits of his increasing and extensive experience. Although the whole of the work has been carefully revised and in several parts enriched for this edition, the chapters of most interest are that in which Bigelow's operation is discussed, and the final one, in which is a record of 500 operations for stone in cases of male adults under the author's care; such a table has never before been compiled by any surgeon. As we have recently drawn attention to Sir Henry Thompson's views on Bigelow's operation, as he expressed them at Cambridge, and as a résumé of the table of cases was presented to the Medico-Chirurgical Society two years ago, and commented on by us then, we need not notice them at length now. Suffice it that this edition is far more valuable to the practical surgeon than the last, and well worthy of the reputation of its accomplished author.

Leçons Cliniques sur l'Uréthrotomie Interne faites à l'Ecole pratique de la Faculté de Médecine de Paris. Par le Dr. Delefosse, et recueilliés par E. PIOGEY. Paris: J. B. Baillière et Fils. 1880.

M. Delefosse is an ardent advocate for the operation of internal urethrotomy, and in these five clinical lectures he has given forcibly and well "reasons for the faith that is in him." He regards dilatation as par excellence the treatment for stricture of the urethra; but in very nearly all cases in which it is impossible or difficult to carry it out, or in which it fails to give a thoroughly good result, he considers internal urethrotomy to be the best plan to be adopted. The use of caustics, which so long held their place in France, he rejects altogether, and he has nothing good to say of "1 upture" or "forcible dilatation." He follows Civiale, Caudmont, and Thompson in preferring a urethrotome cutting from behind forwards to one acting in the opposite direction. Delefosse does not look upon urethrotomy as a mode of cure of an organic stricture, and he is at pains to point out what are the conditions most favourable to a slow recontraction of the strictured part. In his opinion they are, first, a complete division of the stricture tissue at one point; second, the ex- 